\title{
Evaluating Highly Effective Criteria on the Development of Urban Wastewater Treatment Plants with Sustainable Approach
}

\author{
Mohsen moradi. \\ MSC, Department of civil Engineering, \\ central tehran Branch, Islamic Azad University, tehran, Iran. \\ Javad Majrouhi Sardroud \\ Assistant Professor, Department of Civil Engineering, \\ Islamic Azad University, tehran, Iran.
}

\begin{abstract}
Today, the international community considers sustainable development as an exclusive agreement between economy, environment, and social objectives to facilitate the use of resources that are now available by posterity. On the other hand, water problems in Iran resulted from numerous factors such as rainfall shortage and mismanagement make clear the need for examining the sustainable development issue. Besides, it is also posed to need for refinement of sewage in order to compensate dehydration as much as possible. In this research, it is tried to be examined the existing international standards on the ranking of urban infrastructures, including water and wastewater treatment plants in the absence of adequate laws. To be introduced proposition of its development on an indigenous model of metropolitan of Tehran city applying a set of changes and, with this, it will be performed correct and accurate management, and it is led to be highlighted the issue of sustainable development in metropolitan of Tehran and, subsequently, Iran. Finally, it is conducted ranking of the main indexes and amount of effect of the evaluated indexes and is introduced the most important index is economical one which plays a critical role in sustainability and localization of these systems in Tehran. Then, it is arranged environmental, social, and planning indexes, respectively.
\end{abstract}

\section{Introduction}

As is well known, Iran has an urban and rural binary structure caused by the government placing a higher priority on allocating resources to urban and industrial development (Zhang et al 2014). Besides, Water resources management is a set of various management measures aimed at utilizing water resources and reducing economic, social, and environmental damages. Sustainable development is an exclusive agreement between economy, environment and social objectives of a society in order to use the future generations from the natural possibilities that, today, are available to the world (Martinx, 2015). On the other hand, given the water is a critical resource in the sustainability of the environment, it also demands special attention to use practical solutions in the water and wastewater issue. Using automation of water and wastewater help us increasingly in the process and advancing of urban sustainable development purposes.

On the other hand, the world is increasingly touching risk of reducing the specific freshwater resources to drinking and agriculture; however, planned reuse of water obtained from wastewater has only taken two or three decades as demand for water has considerately increased due to technological development, population growth and urbanization (Vignes Warren et al. 2001). Crisis of water in Iran has also known by all the people at present is influenced by three main factors: population growth, inefficient agriculture, and a serious desire for development (Madani, 2002). In addition to the wrong strategies and disability of managers for employment in the other sections, some negligence creates industries, which require water throughout the country even in desert areas. Similarly, this disability has caused to issue a license for superfluous digging of deep and semi-deep agricultural and industrial wells. Along with these licenses, insufficient supervision, as well as some other problems, have caused thousands of illegal wells throughout the country which are also exploiting at present. As a result, the level of water of the country's plains has been sharply decreased. The weather phenomena, excessive consumption of domestic subscribers, exhaustion of water transmission system as well as consecutive droughts have also strengthened it. 
Decision-making on the sustainable and integrated management of water resources requires a comprehensive attitude to the biologic and social economic effects of water resources as well as the precautionary principle that employs an anticipatory attitude towards irreversible and potentially harmful environmental and social impacts(M. Bryce et al,2014). Decision-making problems of water resources management are complicated because of various decision-making criteria and indexes. To achieve a specific goal in the water resources management, there are numerous solutions, each of which finds a preference for different environmental, social, economic, and organizational problems from a different point of views. These requirements are led to use the multi-criteria decision-making methods, which their aim is to select the best response among the possible solutions.

In the present study, it has been tried to be examined the existing international standards on the ranking of urban infrastructures including water and wastewater treatment plants in the absence of effective laws and to be introduced proposition of its development on an indigenous model of metropolitan of Tehran applying a set of changes and, hereby, it will be performed a correct and accurate management and it is led to be highlighted the issue of sustainable development in metropolitan of Tehran and, subsequently, Iran. Finally, it is conducted ranking of the main indexes and amount of effect of the evaluated indexes and it is introduced the most important index is economical one which plays a critical role in sustainability and localization of these systems in Tehran. Then, it is arranged environmental, social and programming indexes, respectively. In addition, it is introduced the results of the formation of a legislative workgroup as the most important solution to play a key role in order to apply the proper policies led to suitable changes.

\section{Background}

In the research published in the form of a scientific-research article in 2014 by Jose Manual Diaz Sarachaga, to determine sustainability indexes of the existing water pressure sensors in water distribution systems was presented a methodology. In 2009, he studied general sustainability indexes which have been in practical presented to formulate general policies. In an article provided in Germany in 2002 conducted in two municipalities in two different cities of Germany using AKWA-2100 project it was considered three scenarios with long-term perspective until 2050 to introduce technological, organizational and inter-organizational innovations as integrated, sustainable and environment-friendly alternative systems. In an article, Diaz-Sarachaga focused on the sustainable infrastructure ranking systems in urban development and in another article entitled "evaluation of sustainability of urban water distribution systems", he investigated performance of urban water distribution systems and importance of sustainability approach (James, 2014). In 2002, Walz and Hiessl evaluated urban water infrastructures from point of view of sustainability and designing (Walz \& Hiessl, 2002). In an article entitled "optimal design of wastewater networks using genetic algorithm", Afshar and Sotoodeh investigated and analyzed possibility of using the genetic algorithm method for optimal design of wastewater networks. Accordingly, it has been solved the problem of optimal design of wastewater networks using a set of different designing variables and compared their results with each other (Afshar \& Sotoodeh, 2006).

In a study conducted by Molinos-Senante in 2011, it was studied economic feasibility study for implementing wastewater projects. In this research, it was used cost-benefit analysis in order to develop a systematic decisionmaking supportive tool in implementing these projects and, accordingly, the most important environmental indexes were evaluated to implement wastewater projects based on the economic feasibility study indexes (Molinos-Senante, 2011). Furthermore, in another study, author has examined cost-benefit analysis to implement water projects and reused these projects for environmental purposes and evaluated economic feasibility study of reusing water in treatment plants by case study in 13 wastewater treatment plants in Valencia, Spain. Results obtained from this research showed that there is a good economic benefit if it is used systematic systems to implement and utilize water projects and reuse them in this area and it will be also led to improve implementation of environmental processes in addition to economic improvement of water consumption (Molinos-Senante, 2012). In his article, Fayek Aziz has investigated the most important executive problems of wastewater construction projects by case study in Egypt. On the results of this research, factors such as organizational weakness, failure of suppliers of raw materials, governmental regulations and delay in transportation system are identified and introduced as some of the most important barriers to implement and utilize properly the water and wastewater projects (Fayek Aziz, 2013). 


\section{Methodology}

Methodology of this research on the purpose it is applied of type and is descriptive-analytic of type based on the method. It is used decision-making criteria with multiple indexes after collecting data on all options due to determined indexes in order to evaluate and select the most preferred index by relevant sub-groups and to prioritize them. Among various methods which there are in the field of decision-making by multiple indexes, multi-criteria decision-making method (AHP) is selected for this research because of its advantages than the other methods. Indexes obtained by library study and interview with experts and specialists are identified in the form of four general categories (level 1) and 20 sub-indexes (level 2), then it will be provided 20 of a questionnaire based on the experts in order to obtain the amount of their importance and whether identified factors are in fact important and effective ones or not. Questionnaires were completed and collected by experts and specialists of the industry including specialist personnel and managers. It will be considered all of the studied people by interview and questionnaire with a subscription called building mass maker (building industry contractor). Statistical population is water and wastewater industry engineers. Then, it will be prepared 50 of a questionnaire based on the experts in order to obtain the amount of their importance and whether identified factors are in fact important and effective factors or not. Sampling method used in this study is a combination of simple and accessible random methods. It should be noted that it has been used Morgan table to determine sample size and number of sample size with statistical population of this research have been estimated 44 people.

\section{Hierarchical analysis method}

Hierarchy analysis process is one of the most comprehensive designed systems for multi-criteria decision-making, because this technique allows to formulate the problem as hierarchy and, also, to consider different qualitative and quantitative criteria in the problem. This process involves various options in decision-making and allows to analyze sensitivity on the criteria and sub-criteria. In addition, it creates a basis for a paired comparison facilitates judgment and calculations. Similarly, it shows the amount of compatibility and incompatibility of decisionmaking that it is one of the privileged advantages of this technique in multi-criteria decision-making. Further, it has a strong theoretical basis based on evident principles (Triantaphyllou, 2002).

In the hierarchical analysis process, elements of each level has been compared to its relevant element at the higher level in a pair and it is calculated their weight called "relative weight". Then, it is determined final weight of each option by integration of relative weights called "absolute weight". All comparisons in hierarchical analysis process are conducted in pairs. It can always calculate the amount of decision compatibility in this process and judge on being good and bad and/or acceptable or not. Range of being acceptable incompatibility in each system depends on decision-maker, but, in general, it is proposed hourly. If incompatibility is more than 1.0, decision-maker should review his/her judgments. AHP algorithm is presented as following steps (Ghodsipour, 2002):

1) Formation of a hierarchical structure (purpose, criteria, options)

2) Make paired comparisons

3) Normalize the paired comparison

4) obtaining the average of the arithmetic of each matrix level to the normalized pairwise comparison (relative weight).

5) Multiplying the relative weights of indicators in the average of the options list.

6) Ranking options

7) Measure the inconsistency rate 


\section{Data analysis}

In Table 1, it has been presented the given indexes and sub-indexes in this study. In this research, it will be examined 4 main indexes and 20 sub-indexes.

Table 1

\begin{tabular}{|c|c|c|c|}
\hline method & Subordinate index & row & Main Indicators \\
\hline \multirow{5}{*}{$\begin{array}{r}\text { Establishment of a } \\
\text { working group of relevant } \\
\text { authorities for the } \\
\text { formulation of } \\
\text { comprehensive laws to } \\
\text { modify the pattern of } \\
\text { consumption }\end{array}$} & $\begin{array}{l}\text { The cost of implementing the project (capital, } \\
\text { repair, maintenance,...) }\end{array}$ & $\mathrm{A}_{11}$ & \multirow[t]{6}{*}{$\begin{array}{l}\mathrm{A}_{1} \text {-Economic } \\
\text { Indicators }\end{array}$} \\
\hline & $\begin{array}{c}\text { Necessary time to be allocated for } \\
\text { implementation }\end{array}$ & $\mathrm{A}_{12}$ & \\
\hline & Utilizing tools for reducing consumption & $\mathrm{A}_{13}$ & \\
\hline & Economic efficiency & $\mathrm{A}_{14}$ & \\
\hline & $\begin{array}{l}\text { Process Stability and Flexibility of the Water } \\
\text { and Sewage System }\end{array}$ & $\mathrm{A}_{15}$ & \\
\hline \multirow{4}{*}{$\begin{array}{r}-\mathrm{P}_{2} \\
\text { Mechanization of Agriculture } \\
\text { and Irrigation by Crop } \\
\text { Improvement and Hydro- } \\
\text { Ecology of the Region }\end{array}$} & Proximity to other industries & $\mathrm{A}_{16}$ & \\
\hline & Educational structure & $\mathrm{A}_{21}$ & \multirow[t]{6}{*}{$\mathrm{A}_{2}$-Social Index } \\
\hline & occupation & $\mathrm{A}_{22}$ & \\
\hline & $\begin{array}{c}\text { population density region (population growth } \\
\text { rate) }\end{array}$ & $\mathrm{A}_{23}$ & \\
\hline \multirow{4}{*}{$\begin{array}{l}\text { Calculation of the true value } \\
\text { of water and waste collection } \\
\text { to create economic incentives }\end{array}$} & Non-dependence and localization & $\mathrm{A}_{24}$ & \\
\hline & Technology maturity and strategic simplicity & $\mathrm{A}_{25}$ & \\
\hline & Culture making & $\mathrm{A}_{26}$ & \\
\hline & Environmental and consuming laws & $A_{31}$ & \multirow{5}{*}{$\begin{array}{l}\boldsymbol{A}_{\mathbf{3}}- \\
\text { Environmental } \\
\text { Index }\end{array}$} \\
\hline \multirow{7}{*}{$\begin{array}{r}\text { Utilization of surface water } \\
\text { and sewage treatment } \\
\text { methods of the world }\end{array}$} & Climate and geographical conditions & $\mathrm{A}_{32}$ & \\
\hline & Safety and compliance with global standards & $\mathrm{A}_{33}$ & \\
\hline & Beauty of perspectives & $\mathrm{A}_{34}$ & \\
\hline & Distance from Protected Areas & $\mathrm{A}_{35}$ & \\
\hline & Existence of regional development plans & $\mathrm{A}_{41}$ & \multirow{3}{*}{$\begin{array}{l}\boldsymbol{A}_{\mathbf{4}} \text {-Planning } \\
\text { Index }\end{array}$} \\
\hline & Existence of industrial development plans & $\mathrm{A}_{42}$ & \\
\hline & The existence of land classification schemes & $\mathrm{A}_{43}$ & \\
\hline
\end{tabular}

After determining indexes and sub-indexes, it is first entered the corresponding paired comparison matrix to main indexes in Expert Choice software for ranking of main indexes and then it is recognized their weight software based on AHP algorithm. In Figure 1, it is illustrated hierarchical structure of given model.

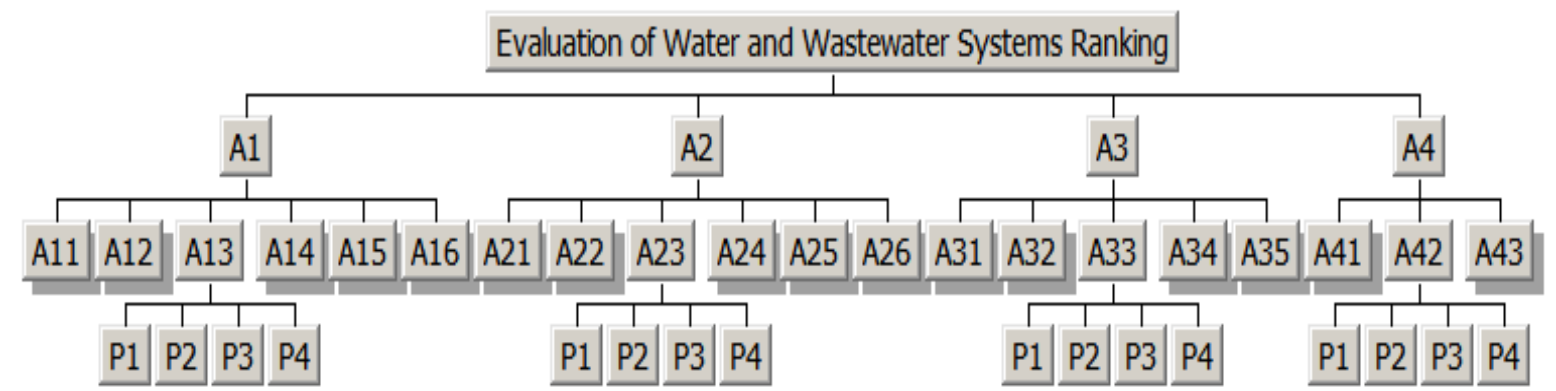

Figure 1

After implementing step of paired comparison, it is calculated final weight of data and compatibility coefficient. Compatibility coefficient in all cases was calculated less than 1.0 and it was proved compatibility of the system. Charts of Figures 2 to 6 are related to the results of final weight of main indexes and sub-indexes. According to the chart of Figure 2, standard economic index for developing urban wastewater systems in Tehran city is along with the sustainable approach. 
Priorities with respect to:

Evaluation of Water and Wastewater Systems Ranking

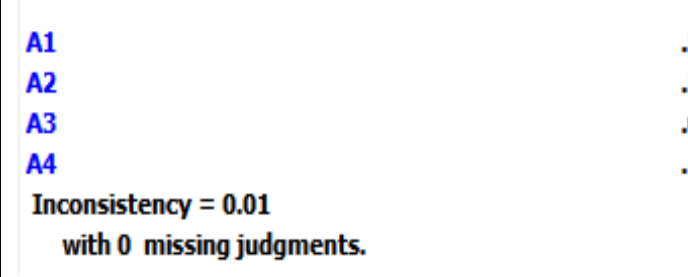

.559

.228

.078

.135

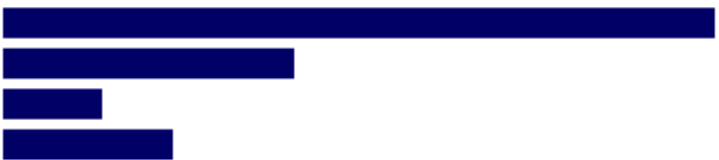

with 0 missing judgments.

\begin{tabular}{|c|c|c|}
\hline \multicolumn{3}{|c|}{ Figure 2-main indexes weight } \\
\hline $\begin{array}{l}\text { Priortities with respect to: } \\
\text { Evaluation of Water and Wastewater Systems Ranking } \\
>A 2\end{array}$ & $\begin{array}{l}\text { Priorities with respect to: } \\
\text { Evaluation of Water and Wastewater Systems Ranking } \\
>\text { >A1 }\end{array}$ & \\
\hline .257 & A11 & 18 \\
\hline .233 & A12 & 65 \\
\hline .055 & A13 & 78 \\
\hline . 043 & A14 & 83 \\
\hline 102 & A15 & 12 \\
\hline A26 & & $43=$ \\
\hline $\begin{array}{l}\text { Inconsistency }=0.08 \\
\text { with } 0 \text { missing judgments. }\end{array}$ & $\begin{array}{l}\text { Inconsistency }=0.05 \\
\text { with } 0 \text { missing judgments. }\end{array}$ & \\
\hline Figure4- social main indexes weight & Figure3- economic $\mathrm{m}$ & nain indexes weight \\
\hline $\begin{array}{l}\text { Prioirities with respect to: } \\
\text { Evaluation of Water and Wastewater Systems Ranking } \\
>\mathrm{A} 4\end{array}$ & $\begin{array}{l}\text { Priorities with respect to: } \\
\begin{array}{l}\text { Evaluation of Water and Wastewater Systems Ranking } \\
>A 3\end{array}\end{array}$ & \\
\hline & A31 & 424 \\
\hline .625 & $\begin{array}{l}\text { A32 } \\
\text { A33 }\end{array}$ & ${ }_{280}^{138}$ \\
\hline .238 & A34 & .057 \\
\hline $\begin{array}{l}\text { A43 } \\
\text { Inconsistency }=0.02 \\
\text { with } 0 \text { missing judgments. }\end{array}$ & $\begin{array}{l}\text { A35 } \\
\text { Inconsistency }=0.03 \\
\text { with } 0 \text { missing judgments. }\end{array}$ & $101 \square$ \\
\hline Figure6-planning main indexes weight & Figure5- environmental & 1 main indexes weight \\
\hline
\end{tabular}

Figures 2-6

Of the relevant criteria to economic factor, "designer's implementation cost index (investment, repair, maintenance and ...)" and "economic efficiency" index have the highest weight. Therefore, it can find that the implementation cost and efficiency are the most important criteria for specialists of this sector.

Charts of Figures 7 to 12 and Table 2 show final weight of four proposed solutions in Table 1 in each of subindexes of main economic factor.

As observed due to the results of final weight of solutions in economic factor criteria, the third solution, namely, calculation of water real value and waste collection for making economic motivation has been selected as the most appropriate case in the design implementation cost and efficiency criteria which was identified as the most important criteria in prior step. 


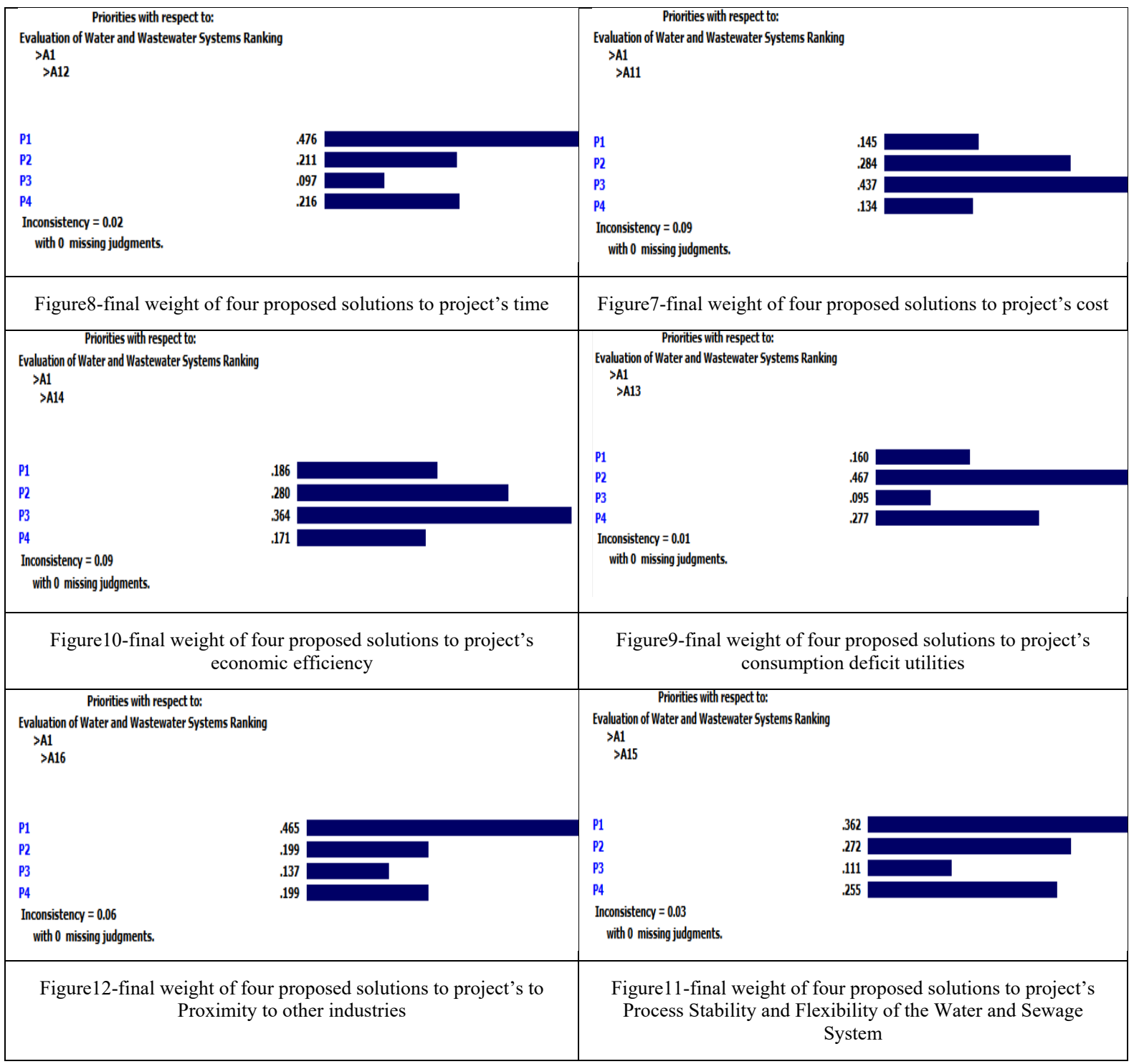

Figures 7- 12

Table 2- The weight of sub-indexes relative to the economic criterion

\begin{tabular}{|c|c|c|c|c|}
\hline index & \multicolumn{4}{|c|}{ Index weight } \\
\cline { 2 - 4 } & $\mathbf{P}_{\mathbf{1}}$ & $\mathbf{P}_{\mathbf{2}}$ & $\mathbf{P}_{\mathbf{3}}$ & $\mathbf{P}_{4}$ \\
\hline $\begin{array}{c}\text { The cost of implementing the project (capital, repair, } \\
\text { maintenance,...) }\end{array}$ & $0 / 145$ & $0 / 284$ & $0 / 437$ & $\mathbf{0} / \mathbf{1 3 4}$ \\
\hline Necessary time to be allocated for implementation & $0 / 476$ & $0 / 211$ & $0 / 097$ & $\mathbf{0 / 2 1 6}$ \\
\hline Utilizing tools for reducing consumption & $0 / 160$ & $0 / 467$ & $0 / 095$ & $\mathbf{0} / \mathbf{2 7 7}$ \\
\hline Economic efficiency & $0 / 186$ & $0 / 280$ & $0 / 364$ & $\mathbf{0} / \mathbf{1 7 1}$ \\
\hline $\begin{array}{c}\text { Process Stability and Flexibility of the Water and Sewage } \\
\text { System }\end{array}$ & $0 / 362$ & $0 / 272$ & $0 / 111$ & $\mathbf{0 / 2 5 5}$ \\
\hline Proximity to other industries & $0 / 465$ & $0 / 199$ & $0 / 137$ & $\mathbf{0} / \mathbf{1 9 9}$ \\
\hline
\end{tabular}

Charts of Figures 13 to 18 show final weight of all four proposed solutions in Table 1 in each of sub-indexes of main social factor.

In culture criteria of social indexes which obtained the highest weight, the fourth solution, namely, use and utilize surface water and modern wastewater refinery methods in the world was realized as the most appropriate solution and, in educational structure criteria which obtained the second rank among social indexes, first solution or, in other words, formation of a workgroup of relevant authorities to codify the comprehensive laws in order to improve consumption pattern was realized as the most appropriate one. 


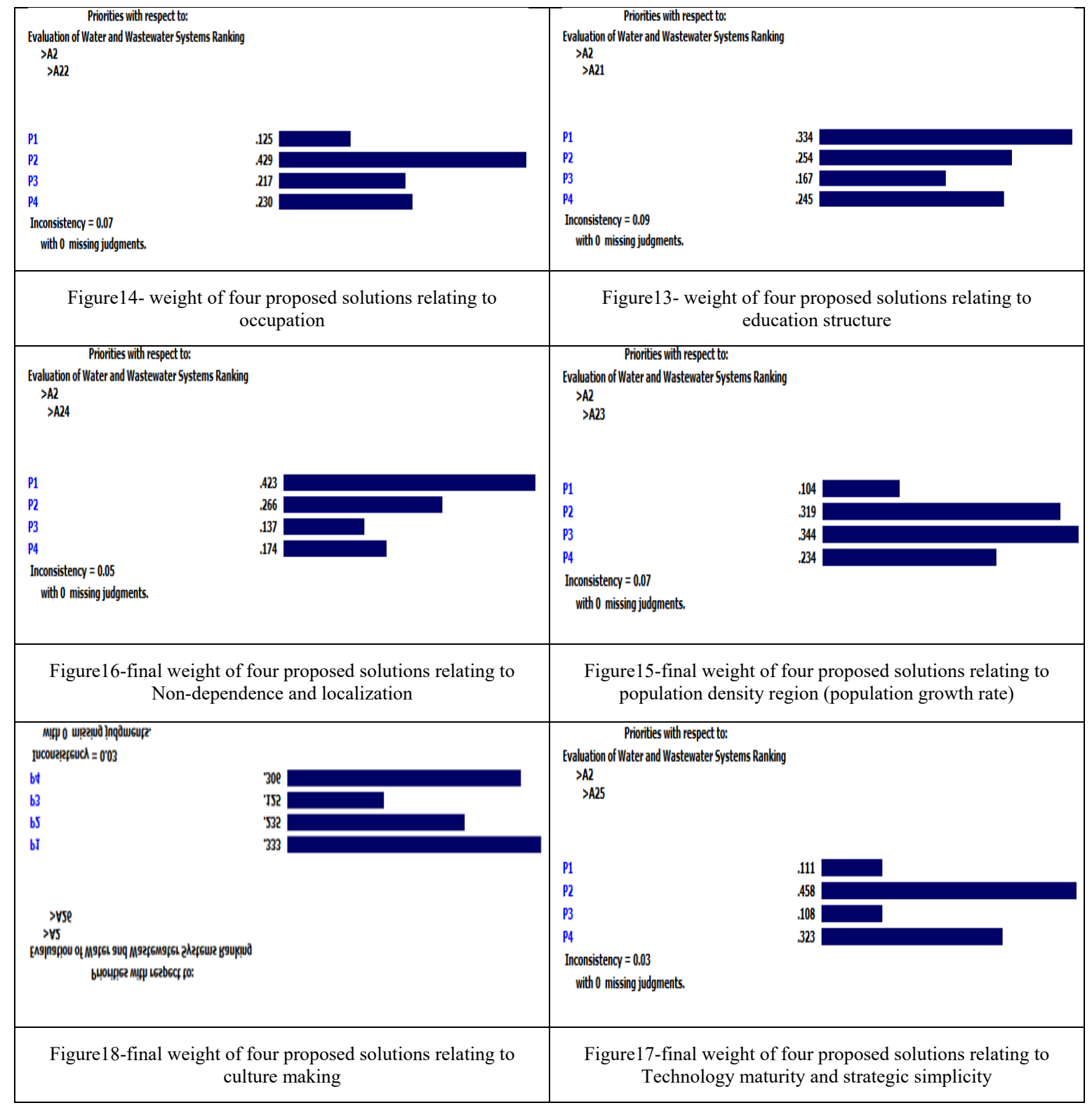

Figures 13-17

Charts of Figures 19 to 23 and Table 3 show final weight of all four proposed solutions in Table 1 in each of subindexes of main environmental factor. 


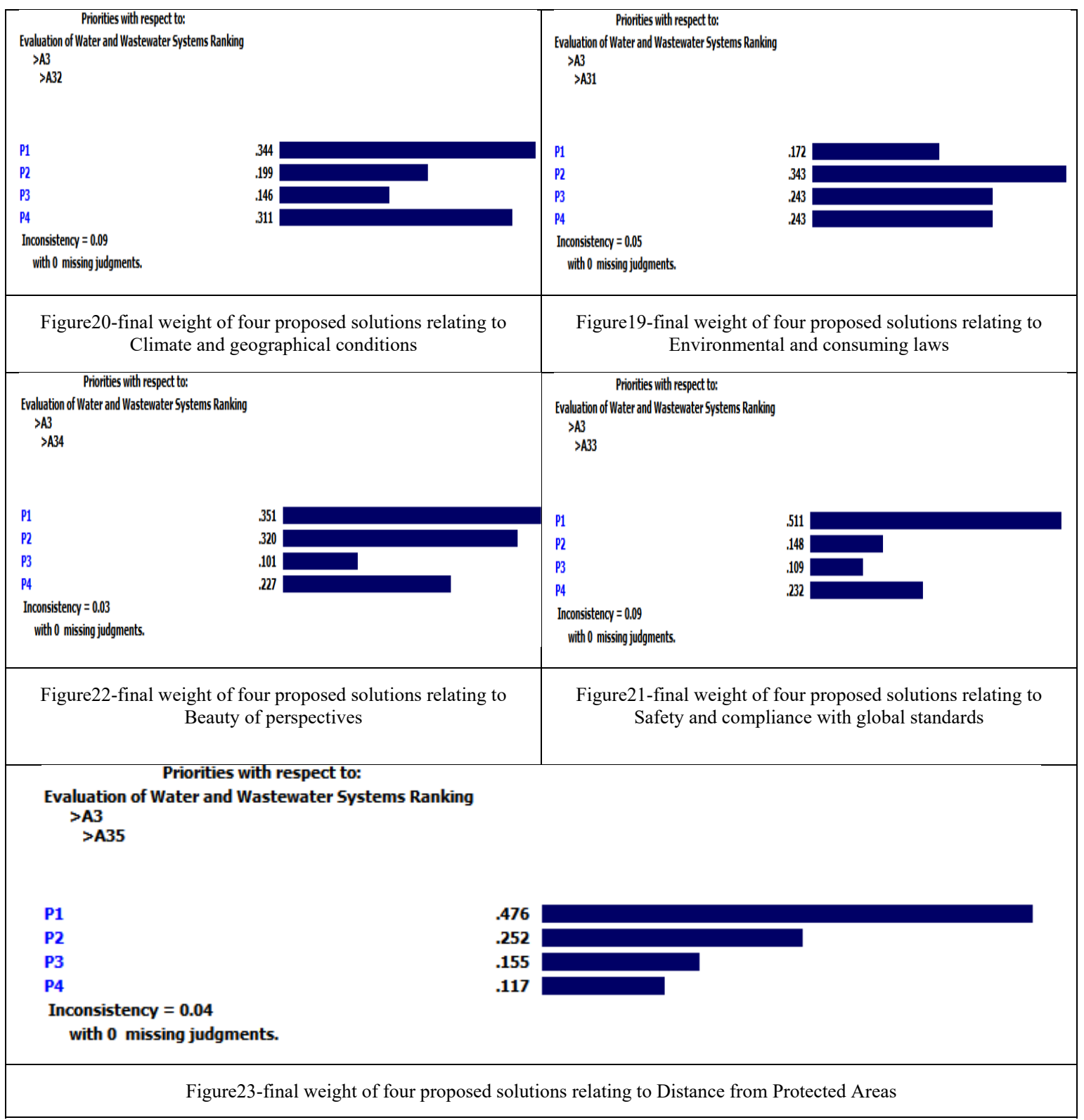

In criteria of environmental laws and laws governing on the consumption of environmental indexes which obtained the highest weight, the second solution, namely, mechanizing agriculture and irrigation with improvement of culture and hydro-ecology power of area is realized as the most appropriate solution.

Table3- Sub-index weight relating to environmental criteria

\begin{tabular}{|c|c|c|c|c|}
\hline \multirow{2}{*}{ Indicator } & \multicolumn{3}{|c|}{ Indicator Weights } \\
\cline { 2 - 5 } & $\mathbf{P}_{\mathbf{1}}$ & $\mathbf{P}_{\mathbf{2}}$ & $\mathbf{P}_{\mathbf{3}}$ & $\mathrm{P}_{4}$ \\
\hline Environmental and consuming laws & $\mathbf{0 / 1 7 2}$ & $\mathbf{0 / 3 4 3}$ & $\mathbf{0 / 2 4 3}$ & $0 / 243$ \\
\hline Climate and geographical conditions & $\mathbf{0 / 3 4 4}$ & $\mathbf{0} / \mathbf{1 9 9}$ & $\mathbf{0 / 1 4 6}$ & $0 / 311$ \\
\hline $\begin{array}{c}\text { Safety and compliance with global } \\
\text { standards }\end{array}$ & $\mathbf{0 / 5 1 1}$ & $\mathbf{0 / 1 4 8}$ & $\mathbf{0 / 1 0 9}$ & $0 / 232$ \\
\hline Beauty of perspectives & $\mathbf{0 / 3 5 1}$ & $\mathbf{0 / 3 2 0}$ & $\mathbf{0 / 1 0 1}$ & $0 / 227$ \\
\hline Distance from Protected Areas & $\mathbf{0 / 4 7 6}$ & $\mathbf{0 / 2 5 2}$ & $\mathbf{0 / 1 5 5}$ & $0 / 117$ \\
\hline
\end{tabular}

Charts of Figures 24 to 26 and Table 4 show final weight of all four proposed solution in Table 1 in each of subindexes of main planning factor. In the most important criteria of this index which is regional development designs, the first solution, namely, formation of a workgroup of relevant authorities to codify comprehensive laws in order to improve consumption pattern was realized as the most appropriate one. 


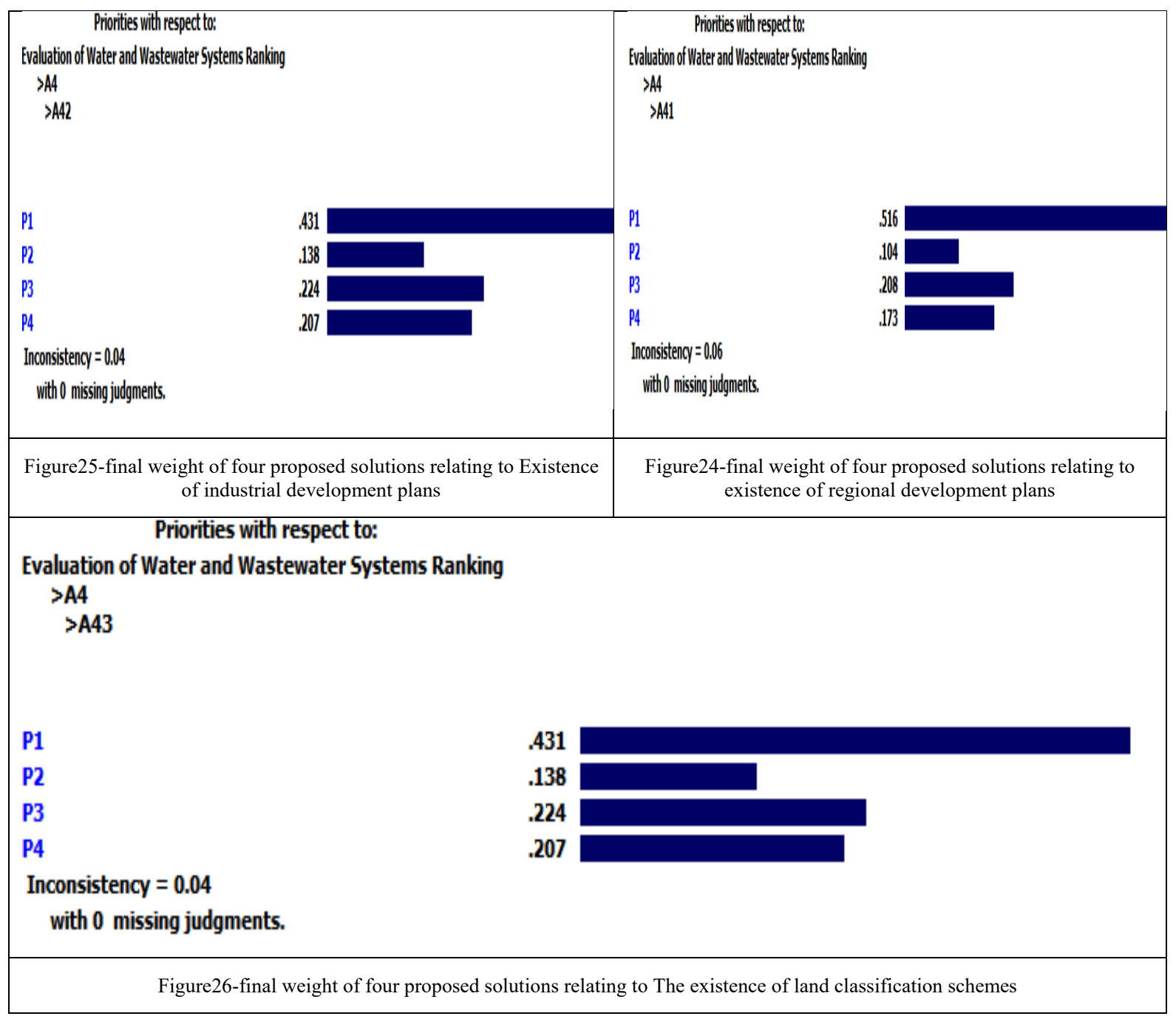

Table 4- Sub-index weight relating to the planning criterion

\begin{tabular}{|c|c|c|c|c|}
\hline \multirow{2}{*}{ Index } & \multicolumn{4}{|c|}{ Index weight } \\
\cline { 2 - 5 } & $\mathbf{P}_{\mathbf{1}}$ & $\mathbf{P}_{\mathbf{2}}$ & $\mathbf{P}_{\mathbf{3}}$ & $\mathrm{P}_{4}$ \\
\hline Existence of regional development plans & $\mathbf{0 / 5 1 6}$ & $\mathbf{0 / 1 0 4}$ & $\mathbf{0 / 2 0 8}$ & $0 / 173$ \\
\hline Existence of industrial development plans & $\mathbf{0 / 4 3 1}$ & $\mathbf{0 / 1 3 8}$ & $\mathbf{0 / 2 2 4}$ & $0 / 207$ \\
\hline The existence of land classification schemes & $\mathbf{0 / 4 3 1}$ & $\mathbf{0 / 1 3 8}$ & $\mathbf{0 / 2 2 4}$ & $0 / 207$ \\
\hline
\end{tabular}




\section{Discuss}

Generally, results obtained from calculating water and green wastewater ranking systems to develop on the sustainability criteria in Iran and the world using hierarchical analysis method are illustrated in Table 5.

Table 5

\begin{tabular}{|c|c|c|c|c|c|}
\hline $\begin{array}{l}\text { Solution or } \\
\text { suggestion }\end{array}$ & Weight & Subordinate Index & Weight & $\begin{array}{l}\text { Main } \\
\text { index }\end{array}$ & Target \\
\hline \multirow{4}{*}{$\begin{array}{c}\mathrm{P}_{1} \text { - Establishment of } \\
\text { a working group of } \\
\text { relevant authorities } \\
\text { for the formulation } \\
\text { of comprehensive } \\
\text { laws to modify the } \\
\text { pattern of } \\
\text { consumption } \\
0 / 283\end{array}$} & $0 / 318$ & $\begin{array}{l}\text { A11 :implementation cost } \\
\text { (cost of capital, repairs, } \\
\text { maintenance ...) }\end{array}$ & $0 / 559$ & \multirow{6}{*}{$\begin{array}{l}A_{1}: \\
\text { Economic } \\
\quad \text { Index }\end{array}$} & \multirow{20}{*}{$\begin{array}{l}\text { Evaluation } \\
\text { A: Green } \\
\text { water and } \\
\text { wastewater } \\
\text { rating } \\
\text { systems for } \\
\text { development } \\
\text { based on } \\
\text { sustainability } \\
\text { criteria }\end{array}$} \\
\hline & $0 / 165$ & $\begin{array}{l}A_{12}: \text { Necessary time to be } \\
\text { allocated for implementation }\end{array}$ & & & \\
\hline & $0 / 078$ & $\begin{array}{l}A_{13}: \text { Utilizing tools for } \\
\text { reducing consumption }\end{array}$ & & & \\
\hline & $0 / 283$ & $\begin{array}{c}A_{14}: \\
\text { Economic efficiency }\end{array}$ & & & \\
\hline \multirow{6}{*}{ 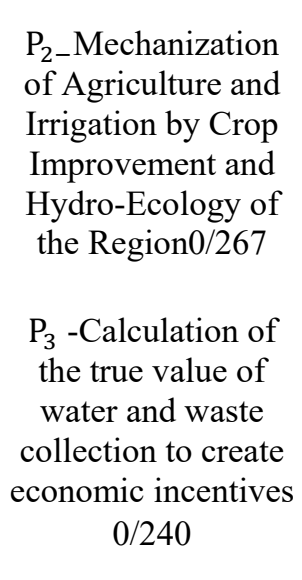 } & $0 / 112$ & $\begin{array}{c}A_{15}: \text { Process Stability and } \\
\text { Flexibility of the Water and } \\
\text { Sewage System }\end{array}$ & & & \\
\hline & $0 / 043$ & $\begin{aligned} A_{16} & \text { :Proximity to other } \\
& \text { industries }\end{aligned}$ & & & \\
\hline & $0 / 257$ & $\begin{array}{c}A_{21}: \\
\text { Educational structure }\end{array}$ & \multirow[t]{6}{*}{$0 / 228$} & \multirow{6}{*}{$\begin{array}{l}A_{2}: \\
\text { Social } \\
\text { Index }\end{array}$} & \\
\hline & $0 / 233$ & $A_{22}:$ Occupation & & & \\
\hline & $0 / 055$ & $\begin{array}{l}\qquad A_{23}: \\
\text { population density region } \\
\text { (population growth rate) }\end{array}$ & & & \\
\hline & $0 / 043$ & $\begin{array}{c}A_{24}: \\
\text { Non-dependence and } \\
\text { localization }\end{array}$ & & & \\
\hline \multirow{10}{*}{$\begin{array}{c}\mathrm{P}_{4} \text {-Utilization of } \\
\text { surface water and } \\
\text { sewage treatment } \\
\text { methods of the } \\
\text { world } \\
0 / 210\end{array}$} & $0 / 102$ & $\begin{array}{c}A_{25}: \\
\text { Technology maturity and } \\
\text { strategic simplicity }\end{array}$ & & & \\
\hline & $0 / 310$ & $\begin{array}{c}A_{26}: \\
\text { Culture making }\end{array}$ & & & \\
\hline & $0 / 424$ & $\begin{array}{c}A_{31} \text { : Environmental and } \\
\text { consuming laws }\end{array}$ & \multirow[t]{5}{*}{$0 / 078$} & \multirow{5}{*}{$\begin{array}{c}A_{3}: \\
\text { Environm } \\
\text { ental } \\
\text { Index }\end{array}$} & \\
\hline & $0 / 138$ & $\begin{array}{c}A_{32}: \text { Climate and geographical } \\
\text { conditions }\end{array}$ & & & \\
\hline & $0 / 280$ & $\begin{array}{c}A_{33}: \text { Safety and compliance } \\
\text { with global standards }\end{array}$ & & & \\
\hline & $0 / 057$ & $A_{34}:$ Beauty of perspectives & & & \\
\hline & $0 / 101$ & $\begin{array}{c}A_{35}: \text { Distance from Protected } \\
\text { Areas }\end{array}$ & & & \\
\hline & $0 / 625$ & $\begin{array}{c}A_{41} \text { Existence of regional } \\
\text { development plans }\end{array}$ & \multirow[t]{3}{*}{$0 / 135$} & \multirow{3}{*}{$\begin{array}{l}A_{3}: \\
\text { Planning } \\
\text { Index }\end{array}$} & \\
\hline & $0 / 238$ & $\begin{array}{cl}A_{42} & \text { :Existence of industrial } \\
& \text { development plans }\end{array}$ & & & \\
\hline & $0 / 136$ & $\begin{array}{l}A_{43}: \text { The existence of land } \\
\text { classification schemes }\end{array}$ & & & \\
\hline
\end{tabular}


As seen in Table 5, economic criteria with weight of 559.0 is the most important one in evaluating water and green wastewater ranking systems to develop on the sustainability criteria, and social, planning and environmental factors are placed in the next ranks with weights of 228.0. 135.0, 078.0, respectively.

According to the technical model results, economic criteria has allocated the highest weight (559.0) to itself. The results show that role of economic factors along with developing of tools and equipment and the leap from the old technologies toward the industrial and developed systems has changed from its traditional situation and today it has been turned to one of the most important factors in promoting a project including civil and sustainable development in water and green wastewater systems. Environmental factors with weight of 078.0.

Finally, in Table 6 it has been displayed final results of the proper structural system selection among the water and green wastewater systems to develop on the sustainability development criteria. As seen in this table, formation of a workgroup of relevant authorities to codify comprehensive laws in order to improve consumption pattern among four proposed solutions has the highest weight (Figure 27).

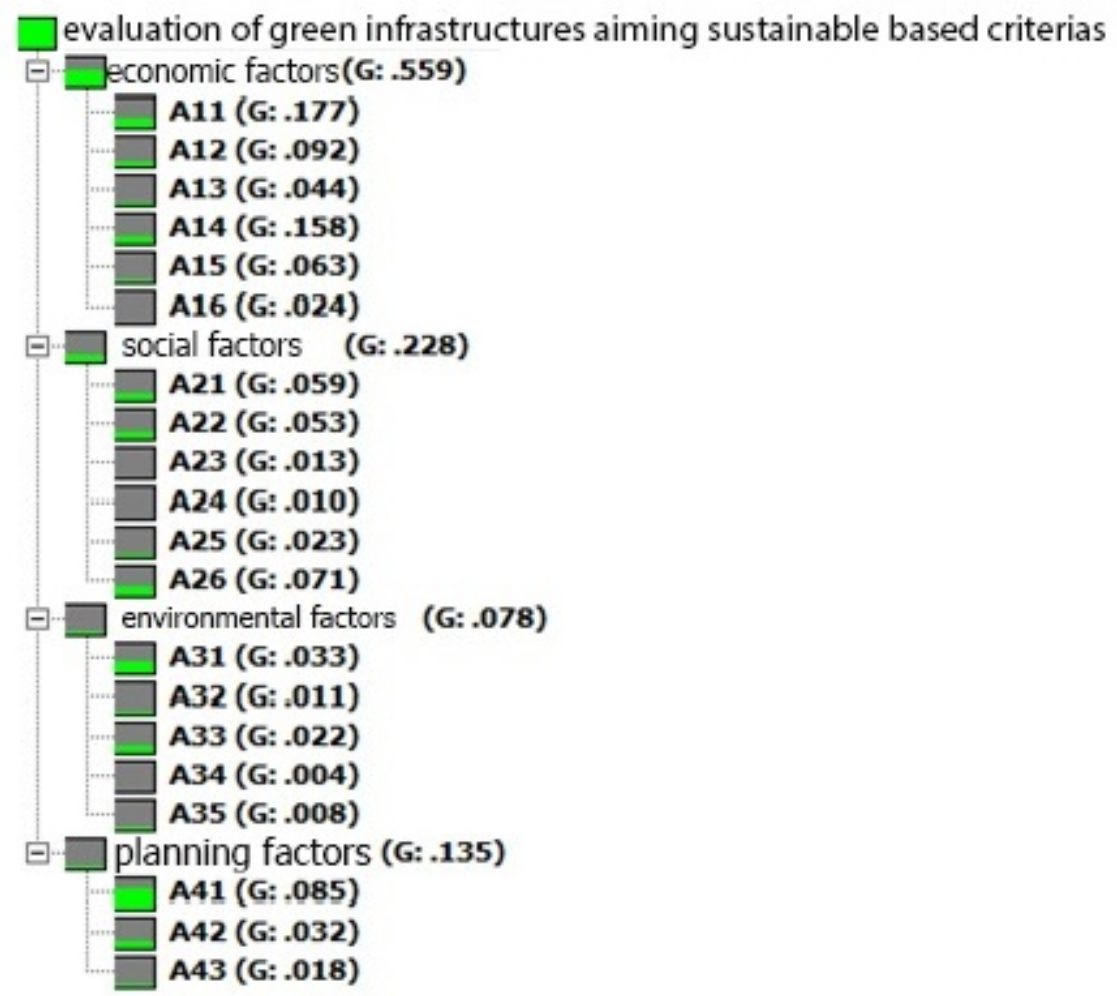

Figure 27-Tree chart Weight of main and secondary indicators

Synthesis with respect to: Evaluation of Water and Wastewater Systems Ranking

Overall Inconsistency = .04

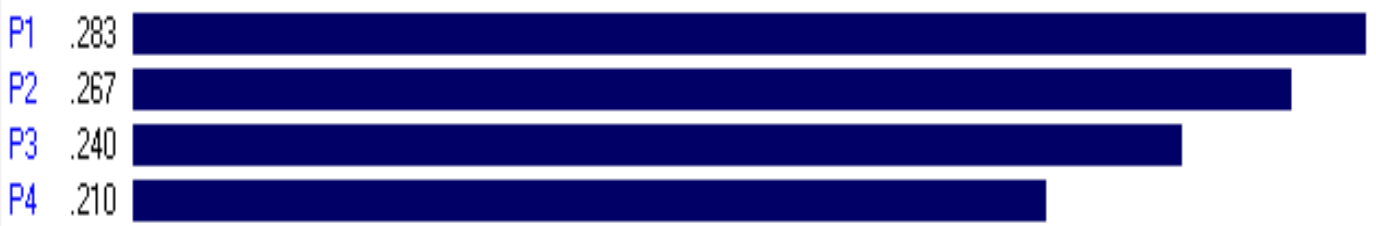

Figure28-Determination of the weight of the proposed solutions 
Table6- Final results of the selection of green water and wastewater systems for development based on sustainable development criteria

\begin{tabular}{|l|c|}
\hline Solution or suggestion & superiority \\
\hline $\begin{array}{l}\text { Establishment of a working group of relevant authorities for the formulation of } \\
\text { comprehensive laws to modify the pattern of consumption }\end{array}$ & $\mathbf{0 / 2 8 3}$ \\
\hline $\begin{array}{l}\text { Mechanization of Agriculture and Irrigation by Crop Improvement and Hydro- } \\
\text { Ecology of the Region }\end{array}$ & $\mathbf{0 / 2 6 7}$ \\
\hline $\begin{array}{l}\text { Calculation of the true value of water and waste collection to create economic } \\
\text { incentives }\end{array}$ & $\mathbf{0 / 2 4 0}$ \\
\hline Utilization of surface water and sewage treatment methods of the world & $\mathbf{0 / 2 1 0}$ \\
\hline
\end{tabular}

In Figures of 29 to 32, it has been displayed types of sensitivity charts including dynamic, performance, gradient, head to head and double-dimensional. As seen in all charts, the first solution, namely, formation of a workgroup of relevant authorities to codify comprehensive laws in order to improve consumption pattern with \%3.28 has been selected as the best solution as well as mechanizing agriculture and irrigation with the improvement of culture and hydro-ecology power of the region, calculation of water real value and waste collection for making economic motivation and use and utilization of surface water and modern wastewater refinery methods in the world are placed in the second to fourth ranks with $\% 7.26, \% 0.24$ and $\% 0.21$, respectively.

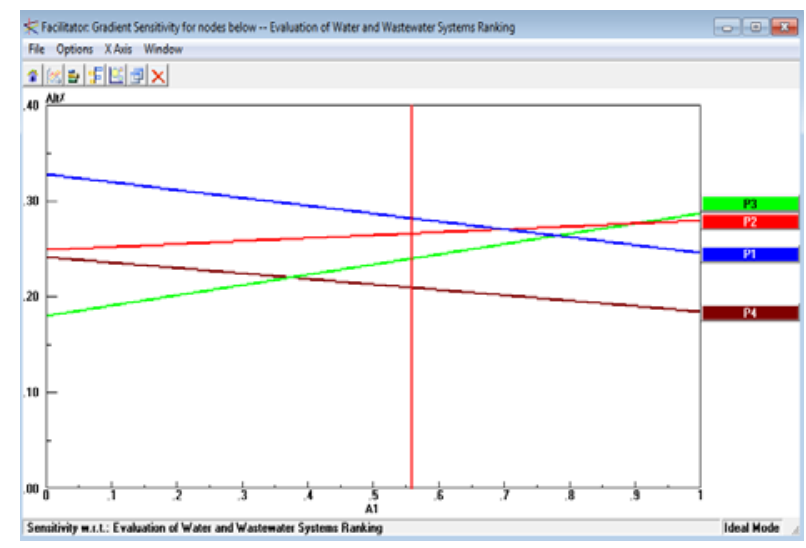

Figure30-Gradient Sensitivity Graph

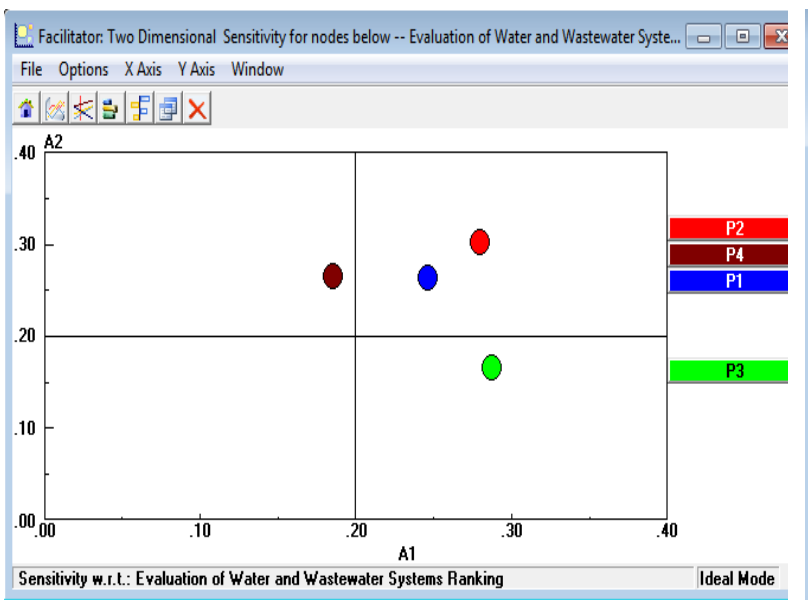

Figure32- Two-dimensional sensitivity diagram

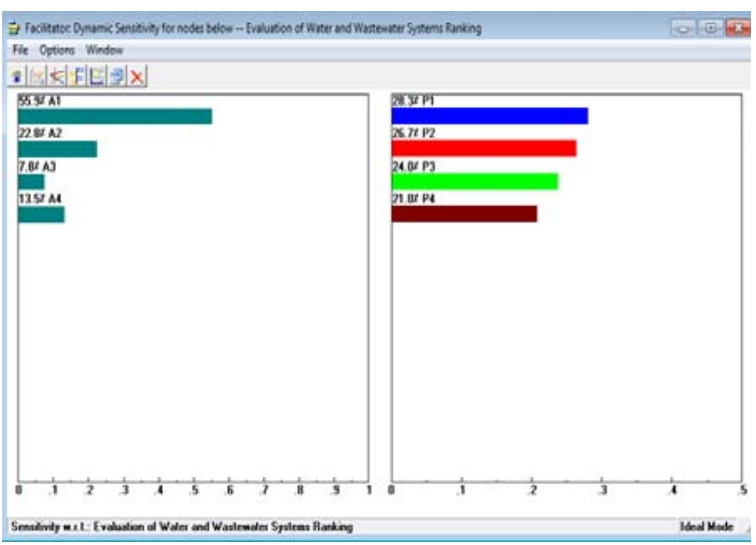

Figure29-Dynamic Sensitivity Diagram

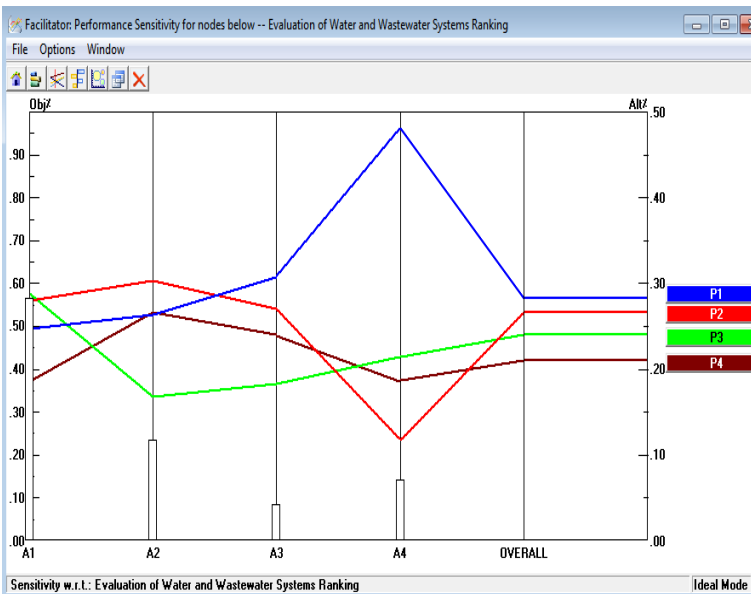

Figure31- Performance sensitivity chart 

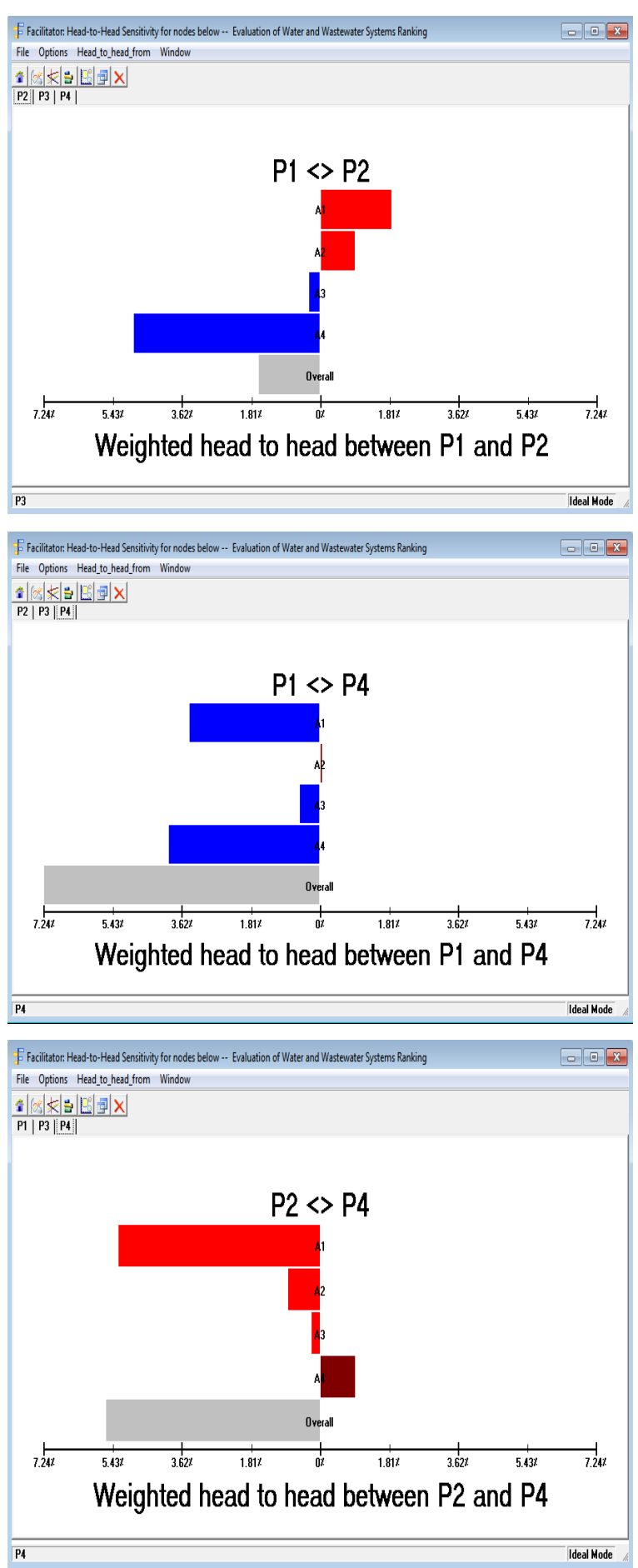
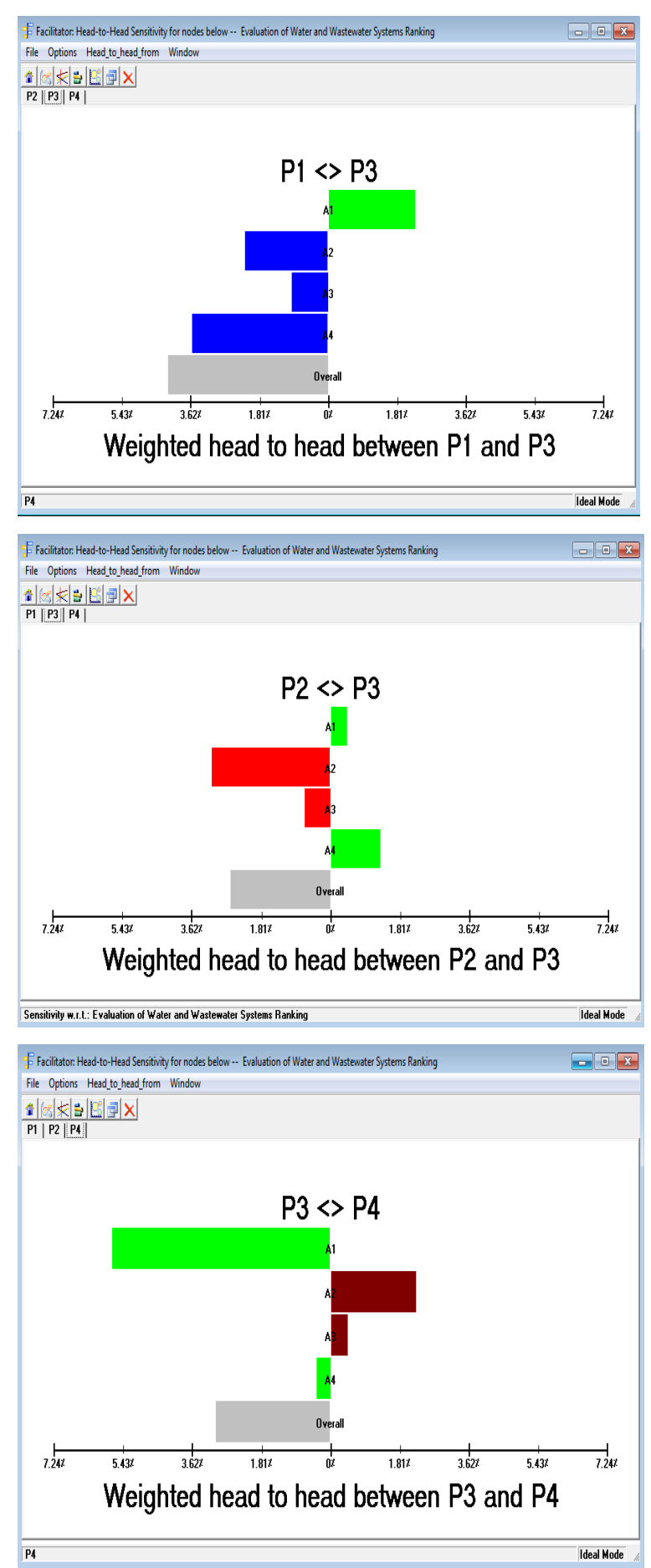

sensitivity diagrams

\section{Conclusion}

In this research, it was proposed an indigenous model for Iran by examining sustainability criteria in the systems of water and wastewater treatment plants for development in Tehran city. To this end, it was first planed main indexes and, then, indexes and sub-indexes and surveyed using a questionnaire by active experts and specialists and engineers in this field. The main indexes in this study have been formed by economic, social, environmental and planning criteria each of which is involved in the sub-indexes to facilitate to select a proper solution or proposition. After determining indexes and sub-indexes, it is entered corresponding paired comparison matrix with the main indexes in Expert Choice software and, then, it is recognized their weight based on AHP algorithm. In other words, it can referred to cost and time management and non-observance of laws and international standards and absence of sufficient supervision within the implementation of project based on the domestic regulations of Iran as one of the most important factors of weakness in the sustainable development in water and 
green wastewater systems. Among effective factors on the main economic index, cost of designer's implementation is the most important sub-index and proximity to other industries is the least important implementation criteria factor. Also, the least and the most important effective indexes on the main economic criteria are as follows, respectively:

Designer's implementation cost, economic productivity, required period for implementing plan, process stability and flexibility of water and wastewater system, use of tools reducing consumption and proximity to other industries. Effective factors on the main index of social criteria are parameters such as foreign independence and localization, regional population density, technology maturity and strategic simplicity, employment, educational structure and culture-making. On the other hand, among effective indexes on the main factor of environmental criteria, sub-index of environmental laws and laws governed on consumption have the highest weight and beauty of landscape has the lowest importance. Due to the existing opinions of experts in this research, the first solution, namely, formation of legislative workgroup fill the gap in laws and its executive supports and mechanization in agriculture also places in the importance rank since it prevents the loss of resources. On the other hand, calculating real water value led consumers more to economy and collecting swages and their refinement will slightly compensate water deficit.

\section{References}

[1] Xiaoling Zhang, Yuzhe Wu, Martin Skitmore, Shijie Jiang, 2015," Sustainable infrastructure projects in balancing urban-rural development: towards the goal of efficiency and equity", Journal of cleaner production,

[2] Vol.107, No.16: 445-454

[3] Madani, Kaveh. "Water management in Iran: what is causing the looming crisis?". Journal of Environmental Studies and Sciences.2002.

[4] Molinos-Senante, M., Hernández-Sancho, F., Sala-Garrido, R., (2011), "Economic feasibility study for wastewater treatment: a costbenefit analysis", Science Total Environment, Vol. 408, No. 20: 4396-4402.

[5] Molinos-Senante, M., Hernández-Sancho, F., Sala-Garrido, R., (2012), "Cost-benefit analysis of water-reuse projects for environmental purposes: a case study for Spanish wastewater treatment plants", Journal of Environment Management, Vol. 92, No. 12: $3091-3097$.

[6] Fayek Aziz, Remon (2013), "Factors causing cost variation for constructing wastewater projects in Egypt", Structural Engineering Department, Faculty of Engineering, Alexandria Engineering Journal, Vol. 52, No. 11: 51-66.

[7] Afshar, Mohammad Hadi, Sotoudeh, (2006). Application of nonlinear programming to optimize the design of sewage networks, Sharif Journal of Research, No 35, pages 25-26

[8] James M. Bryce, Gerardo Flintsch, Ralph P. Hall, (2014). A multi criteria decision analysis technique for including environmental impacts in sustainable infrastructure management business practices, Transportation Research Part, Vol.32, pages 435-445

[9] Triantaphyllou Evangelos, Ph.D.(2002) MULTI-CRITERIA DECISION MAKING:THEORY AND APPLICATIONS, An introduction to the mathematics of the Analytic Hierarchy Process 